\title{
Growth \& Determinants of Fertilizer Consumption in India: Application of Demand and Supply Side Models
}

\author{
Vilas Jadhav ${ }^{1 *}$ and K.B. Ramappa ${ }^{2}$ \\ ${ }^{1}$ Agricultural Development and Rural Transformation Centre [ADRTC], Institute for Social and Economic Change [ISEC], \\ Bengaluru, Karnataka, India \\ ${ }^{2}$ School of Agribusiness and Rural Management, Dr. Rajendra Prasad Central Agriculture University [RPCAU] Pusa, Bihar, India \\ "Corresponding authr: vilasagri@gmail.com (ORCID ID: 0000-0002-2364-2706)
}

Received: 13-06-2021

Revised: 22-08-2021

Accepted: 03-09-2021

\begin{abstract}
This paper estimated the growth of fertilizer consumption in India and forecasted it upto the year 2030 and both supply side and demand side factors which influences it. The results indicated that consumption of fertilizers had been increased at the rate of 4.16 per cent. The demand side determinants like area under irrigation reflected at the rate of 1.42 per cent growth, average minimum support prices showed a growth rate of 7 per cent and a short term institutional credit registered a growth rate of 17 per cent. Area under irrigation and sum of average MSP encourages the fertilizer consumption substantially. The supply side factors viz., production, import and subsidy were influencing the fertilizer consumption significantly. The total fertilizer demand is expected to reach at 57 million tons by 2030 and at the same time, rate of consumption might enhanced to $277 \mathrm{~kg}$ per hectare. It is concluded that import is unavoidable to meet the gap between domestic production and total demand.

\section{Highlights}

(0 Total fertilizer consumption increased at the rate of 4.16 per cent during past and the demand is likely to grow upto 57 million tons and consumption level is expected to reach to $277 \mathrm{~kg}$ per hectare by 2030.

( Fertilizer consumption is influenced by demand side factors like area under irrigation, average minimum support price, institutional credit facilities, etc. and supply side factors like production, import and subsidy significantly.
\end{abstract}

Keywords: demand forecasting, demand side model, determinants, fertilizer consumption, supply side model

Farm sector has always been a dominant player in the course of development of Indian economy. It contributes 14 per cent of the GDP, 11 per cent of exports and almost half of the population is dependent on agriculture for their livelihood FAO (2017). This role has witnessed a transformation from the traditional way of agriculture to modernization of agriculture (Mala, 2013), because the expansion of area under cultivation is not possible and also, arable land is declining (Venugopal, 2004). Apart from diminishing area, there are several other impediments in increasing agricultural production, imbalance use of fertilizer is most important. There are also several other impediments in increasing production like less availability of water, declining soil productivity, the fundamental characteristic of agriculture being exposed to the vagaries of nature and institutional support. Among all, fertilizer is an widely used input and thus has a lot to contribute in increasing agricultural productivity and making the country self-sufficient in food grain production.

How to cite this article: Jadhav, V. and Ramappa, K.B. (2021). Growth \& Determinants of Fertilizer Consumption in India: Application of Demand and Supply Side Models. Economic Affairs, 66(3): 419-425.

Source of Support: None; Conflict of Interest: None (c) 9 
In the absence of any significant breakthrough in agricultural production technology having been achieved in the last decades, the desired levels of targeted agricultural production in the short run to medium run would require more rigorous efforts towards bridging the crop yield gap attainable with existing technology, Malik and Shekhar (2007). They also suggested that the role played by the fertilizers in increasing the productivity of agriculture as one of the modern inputs in existing technology is a ray of hope. The fertilizer consumption in terms of all nutrients has been increasing during the post Green Revolution period, registering a growth rate of 3.24 per cent. Soil is becoming increasingly deficient in many plant nutrients Parama \& Munawery, (2012) due to intensive agriculture and hence use of fertilizers is vital to restore them FAI (2017). A study conducted by Venugopal, (2004) shows that around 50 to 60 per cent increase in food production in India is due to increase in fertilizer applications.

The foodgrain production in India during 2002-03 was 174.78 million tons with a fertilizer consumption of $16.09 \mathrm{mt}$, which increased to 283.37 million tons in 2017-18 (a record increase by 38 per cent corresponding to the previous year) with a fertilizer consumption of 47.20 million tons, Indiastat. com (2018) While the fertilizer consumption, both in absolute terms as well as on per hectare basis, have increased manifold over the years, however the growth in last few years has not been satisfactory. Malik and Shekhar (2007), Mala (2013) and Ramappa (2020) established that increased fertilizer use efficiency leads to economy in use of fertilizers, reduction in unit cost of production, prevention in fall of agricultural productivity, protection of environmental quality and efficient use of other inputs such as irrigation and high yielding varieties (HYVs) in developing countries.

The fertilizer industry in India is the core sector, and second to steel in terms of investment FAO, (2015). The Government of India has taken steps from time to time to promote use and production of fertilizers in the country. All such efforts of the government, introduction of modern technology in the $60 \mathrm{~s}$ and various other factors contributed to the increased consumption of fertilizers in India. Over time, a changing trend of using purchased inputs for cultivation can be observed. Among these modern inputs, fertilizers can be attributed the status of being used by both small and marginal and large farmers. However, there are huge region wise and state wise variations in use of fertilizers too. In this connection, Fertilizer consumption in India is determined by two segments namely demand side and supply side determinants, the major factors such as support prices, area under irrigation, short term institutional credit, and rainfall were used to determine the demand for fertilizers, while the supply was determined using domestic production, imports of fertilizers, and the subsidy allocated to the sector. In many nutrients, domestic production of fertilizers in India is not sufficient to meet the increasing requirement, for which imports are brought to use. Fertilizer subsidy is a huge burden for the government and recently there have been efforts undertaken to reduce the same. Looking into all these dynamics of the sector, it is very essential to forecast the future fertilizer requirement. With this background, the present article analyzed demand and supply sides models for fertilizer consumption and food grain production, identified the determinants of fertilizer consumption and forecasted the demand for fertilizer during the year 2030 in order to achieve sustainable food grain production.

\section{Data and Methodology}

The study has absolutely depended upon secondary information gathered for a period of 34 years (198485 to 2017-18) for which latest data was available. Sources of data such as Fertilizer Statistics 2017-18, FAI (2017), Agricultural Statistics at a Glance 2018, and indiastat.com were used to collect the secondary information. Data related to the area under irrigation and production of these crops was obtained from Agricultural Statistics at a Glance 2018. Moreover, data for the minimum support prices of these selected crops and short term institutional credits were extracted from the Ministry of Agriculture, RBI and NABARD database. Data on the average annual rainfall in India was obtained from the data.gov.in.

Multiple regression models are used to analyze the factors affecting fertilizer consumption in the country in a specified period. Some factors determine the demand for fertilizers while others decides the supply. Thus, the factors are divided accordingly to make two linear models for demand and supply sides. Moreover, the growth rate in 
the per hectare consumption of fertilizers vis-à-vis the growth rate in the yield of fertilizer intensive crops are calculated to analyze the per hectare fertilizer consumption, that is intensity of fertilizer consumption in India. With the help of a logistic model, total fertilizer requirement is forecasted upto the year 2030. Following the trend of GCA in the previous years, it is also being forecasted till 2030. With the help of these indicators, per hectare consumption of fertilizer was computed. The methods used to explain the factors determining using demand for and supply of fertilizer and growth rate of factors, which is influencing the fertilizers consumption. The details of forecasting models are as follows.

(a) Demand Side Model: In the model comprising demand side factors, crops selected are rice, wheat, coarse cereals, cotton, sugarcane, and rapeseed and mustard. The model is as given below:

$$
\begin{gathered}
\text { Consumption }=\alpha 1+\beta 1 \text { PAUI }+\beta 2 \text { SMSP }+ \\
\beta 3 \text { STCL }+u
\end{gathered}
$$

where, Consumption is total fertilizer consumption in '000 tonnes, PAUI is percentage of area under irrigation of the total area under cultivation in million hectares for the selected crops, SMSP is sum of average of minimum support price of food crops and that of commercial crops among the selected crops, STCL is short term credit loans issued in crore Rupees and $\alpha 1$ is intercept of demand side consumption model and $\beta 1, \beta 2$ and $\beta 3$ are the coefficients of PAUI, SMSP and STCL, respectively and $u$ is error term.

(b) Supply Side Model: There are several other determinants of fertilizer consumption like domestic production, import of fertilizers, capacity utilization by the industries, number of sale points, and subsidy allocation. This section is an attempt to study the factors which determine the supply of fertilizers in the country. The supply side model is as follows:

$$
\begin{gathered}
\text { Consumption }=\alpha 2+\gamma 1 \text { NPTP }+\gamma 2 \text { TFIM }+ \\
\gamma 3 \text { CSUB }+u
\end{gathered}
$$

Where, consumption is total fertilizer consumption in '000 tonnes, NPTP is total $N$ and $P$ production in '000 tonnes, TFIM is total fertilizer imports in
'000 tonnes, CSUB is central subsidy issued in crore rupees and $\alpha 2$ is intercept of supply side consumption model and $\gamma 1, \gamma 2$ and $\gamma 3$ are the coefficients of NPTP, TFIM and CSUB, respectively and $u$ is error term.

(c) Factor's Growth Rate: Growth rate of factors which determined are, directly or indirectly, affect the fertilizer consumption in the country and that of total fertilizer consumption itself are calculated. These growth rates are for the period of 34 years starting from 1984 to 2017. The growth rates were calculated using the regression model: $\ln Y=\alpha+\beta$, where, $\ln Y$ is the natural $\log$ value of the variable under consideration. The growth rate is computed using the following formula:

$$
\text { Growth Rate }=(\text { Antilog of } \beta-1) * 100
$$

(d) Forecasting of the Total Fertilizer Demand: For the purpose of forecasting the total fertilizer requirement, total consumption is regressed on time in a logistic model. Other models like growth and exponential were also tested. However, data fits well in logistic model and the forecasted values seem to follow the past trend of fertilizer consumption data well in this model. The GCA was also forecasted using the same logistic model. With the estimates of fertilizer requirement and GCA, per hectare consumption of fertilizer was calculated. The logistic model as follows;

$$
Y t=1 /\left[1 / K+a b^{t}\right]+e
$$

\section{RESULTS AND DISCUSSION}

Increase in the fertilizer consumption is due to the favorable environment like irrigation, spread of HYVs, introduction of the Retention Price Scheme (RPS) in 1977, expansion of phosphate and other complex fertilizers and further inclusion of SSP and ammonium chloride in the RPS, respectively, during 1982 and 1985. This is also due to ease in distribution and affordable prices and improvement in the capacity utilization, especially of $\mathrm{N}$ fertilizers. Sharma and Thaker (2011) pointed out one more reason behind the increase of virtually no change in farm gate fertilizer prices for 10 years (1981-1991). The fertilizer subsidy provided to the fertilizer industries to promote the small and marginal 
farmers by using the subsidized fertilizer crop production activity, but in reality, this provision found to inaccessible to the small and marginal farmers.

\section{Determinants of Fertilizer Consumption}

Indian agriculture has the responsibility to feed more than a billion of peoples, livestock's and agro based industries. To fulfill this need, the only way to increase crop yield with the help of modern inputs is a must. Indian agriculture is the presence of small and marginal farmers in large section of the population. They cannot always afford to use capital inputs like machines and tractors and adopt new technology for crop production. They face resource constraints while doing so and the size of land is not economically suitable too. They are left with the option, use of consumable modern inputs to enhance the land productivity. Out of these consumable inputs, fertilizers are the only input to help in increasing yield. In this connection, the details of factors influencing for fertilizer consumption is analyzed and results are presented in Table 1.

Table 1: Growth Rate of Determinants of Fertilizer Consumption (in per cent)

\begin{tabular}{lll}
\hline $\begin{array}{l}\text { Sl. } \\
\text { No. }\end{array}$ & Particulars & $\begin{array}{l}\text { Compound } \\
\text { growth rate }\end{array}$ \\
\hline 1 & Total fertilizer consumption & 4.16 \\
2 & Total imports & 5.37 \\
3 & Total domestic production & 3.55 \\
4 & Central subsidy & 14 \\
5 & Per cent area irrigated & 1.42 \\
6 & Short term institutional credit & 17.09 \\
7 & Annual rainfall & 0.33 \\
8 & Average MSP & 7.43 \\
\hline
\end{tabular}

Source: Computed using data from Fertilizer Statistics 2018-19 and Agricultural Statistics at a Glance 2019.

Fertilizer consumption is influenced by many determinants. The demand for fertilizers is derived demand i.e., demand for fertilizer is depends on the demand for the crop cultivated and the price received for the same crop. Demand for fertilizers is also influenced by prices of fertilizers, GCA, area under irrigation, availability of credit to the cultivators, etc. The demand side determinants like area under irrigation reflected a growth rate of 1.42 per cent over the 34 years while the average minimum support prices show a growth rate of 7 per cent. The short term institutional credit registers a growth rate of 17 per cent, which is due to the concerted efforts to make credit availability easy to the farmers. Quantum of annual rainfall is important factor affecting for application of fertilizers and has resulted to increase by 0.33 per cent. The results are conformity with the Nagraj (1983).

Subsidies play a huge role in determining fertilizer consumption. They form a major part of the total subsidy expenditure of the government as reflected by 14 per cent of growth rate. Sometimes it is claimed that the structure of fertilizer subsidies leads to the imbalance in use of fertilizers. Indian soils are now deficient in many micro nutrients as well. Thus, managing subsidies such that it will lessen the burden and promote balanced use of all fertilizers is the need of the hour. The import of fertilizer has significantly increased during the study period as reflected by growth rate of 5.37 per cent on the contrary, growth rate of domestic fertilizer production registered by 3.55 per cent. The consumption of fertilizers has been increasing over the period by reflecting the growth rate of 4.16 per cent per annum. However, there are still certain reasons which impede the extensive use of fertilizers. These are explained clearly by Venugopal (2005) as: (i) non-availability of fertilizers in time, (ii) capital/ credit constraints, (iii) not growing crops where fertilizer use is profitable, (iv) non-availability of irrigation water, (v) desired type of fertilizer not available, (vi) higher price than output price, (vii) soil deterioration, and (viii) FYM available. These reasons can be considered valid in the current period too. Therefore, the current consumption pattern of fertilizers in India is repeatedly said to have further scope of efficient and balanced use with increased intensity so that it will improve agricultural profitability.

\section{Demand Side Fertilizer Consumption Model}

Given the importance of the fertilizers, role played in strengthening Indian agriculture, the government has continuously taken up steps to ease the consumption of fertilizer by farmers. There are several factors that contribute to the increase in fertilizer consumption. Among them, MSPs, augmentation of area under irrigation, availability of credit, etc. plays an important role in determining 
the demand of fertilizers from the field. On the contrary, domestic production, total imports of fertilizers, and subsidy extended to the sector are significantly affecting the supply of fertilizers in the country. Increase in the output prices, area under irrigation and credit availability are all institutional factors. They show a decent growth over time. Concerted efforts towards achieving this growth has to be credited, however they have their own limitations too. Not all farmers are able to benefit themselves from support prices. The spread of irrigation has to be intensified too. Moreover, in case of credit, non- institutional sources still show their presence in the agricultural credit system. Keeping in view of all these potential factors, the regression were employed for demand side consumption model and results are presented in Table 2.

Table 2: Regression results for demand side consumption model

\begin{tabular}{|c|c|c|c|c|}
\hline \multicolumn{2}{|c|}{ Sl. No. Variable } & \multicolumn{3}{|c|}{ Coefficient $t$ value Standard Error } \\
\hline 1 & Constant $(\alpha 1)$ & $5939.48^{* * * *}$ & 6.80 & 873.54 \\
\hline 2 & PAUI & $135.84^{* * * *}$ & 5.56 & 24.43 \\
\hline 3 & SMSP & $4.85^{* * * *}$ & 6.82 & 0.71 \\
\hline 4 & STCL & $-2.96^{* * *}$ & -3.09 & 0.96 \\
\hline 5 & Adj. $R^{2}$ value & 0.95 & - & - \\
\hline 6 & $\mathrm{R}^{2}$ value & 0.95 & - & - \\
\hline 7 & F value & $181.35^{* * *+*}$ & - & - \\
\hline
\end{tabular}

Note: ${ }^{* * *}$ denotes values are significant at one per cent level.

Source: Authors Calculations.

The high $\mathrm{R}$ square value (0.95) denotes that 95 per cent of variation in the fertilizer consumption is explained by the variation in the explanatory variables. The model is significant at 1 per cent level and all the variables are also considered as significant at one per cent level. The period under consideration witnessed increasing consumption as the green revolution technology was more or less spread across the states. Moreover, the policy changes made fertilizer prices to fluctuate due to decontrol. As mentioned earlier, increasing the support prices was the alternative policy option adopted. The support prices have been continuously increasing over the period. Though increase in support prices was not successful as a policy alternative to increase fertilizer consumption, the model shows that it does have a significant role to play in determining the consumption of fertilizers. It is well established from the result by increasing one per cent area under irrigation, fertilizer consumption will increase by 135.84 thousand tonnes. Similarly, by increasing one per cent MSP, fertilizer consumption will increase by 4.85 tonnes. Short term institutional loans (STCL) reflected a negative relation, which means by one per cent increasing Short term institutional loans (STCL) the fertilizer consumption will declined by 2.96 tonnes. This may due to discouraged private sectors production and import of chemical fertilizer due to which total supply could not be increased as expected.

\section{Supply Side Consumption Model}

The regression results of supply side consumption model are given in Table 3 . The result shows the importance of domestic production in fertilizer consumption. Increase in domestic production with the efficient capacity utilization will directly affect the fertilizer consumption.

Table 3: Regression Results for Supply Side Consumption Model

\begin{tabular}{lllll}
\hline S1. No. & Variable & Coefficients & $\mathbf{t}$ value & $\begin{array}{l}\text { Standard } \\
\text { Error }\end{array}$ \\
\hline 1 & Constant $(\alpha 2)$ & $601.98^{* * *}$ & 1.45 & 416.25 \\
2 & NPTP & $0.99^{* * *}$ & 28.26 & 0.04 \\
3 & TFIM & $0.70^{* * *}$ & 9.81 & 0.07 \\
4 & CSUB & $0.04^{* * *}$ & 3.86 & 0.01 \\
5 & Adj. R ${ }^{2}$ value & 0.99 & - & - \\
6 & R $^{2}$ value & 0.99 & - & - \\
7 & F value & $1401.30^{* * *}$ & - & - \\
\hline
\end{tabular}

Note: ${ }^{* * *}$ denotes values are significant at $1 \%$ level.

Source: Authors Calculations.

From the table the high R square value (0.99) denotes that 99 per cent variation in the consumption of fertilizers is explained by the variation in the explanatory variables. All the three independent variables in the model such as production (NPTP), import (TFIM) and subsidy (CSUB) are significant at one per cent level with the ' $t$ ' value of 28.26, 9.81 and 3.86, respectively. So, it is important to import the fertilizers to meet the gap between domestic production and total demand since we have less production. In case of $\mathrm{K}$ fertilizers, the country is dependent on imports fully. As discussed in the previous section, imports (TFIM) have 
shown a higher growth as compared to domestic production (NPTP). Therefore, again the need to augment domestic production is emphasized here. Though subsidy becomes a huge burden on the government, it plays a major role in determining the consumption. Therefore, it is important to allocate subsidies in such a way that reduce the burden and promote balanced use of fertilizers.

\section{Forecasting of Fertilizer Demand}

Logistic model used for forecasting of fertilizer demand till the year 2030, is presented in Table 4 . The result shows that total fertilizer demand will be increased by around 7.04 million tons in next five years (i.e. 48.68 million tons during 2025) than now i.e.39.70 million tons. By the year of 2030 the total requirement of fertilizer consumption will be 57.32 million tons. The result also indicate that the forthcoming years will be experienced continuous rise in the fertilizer demand. Hence the domestic production of fertilizer has to be promoted to meet the increasing requirement instead of importing of fertilizers. The estimated gross cropped area during next five years will increased by 2.48 million hectare and by the year of 2030, it will reached to 206.72 million hectare. Similarly, fertilizer consumption will be increased by $32.17 \mathrm{~kg} /$ hectare in next five year and at the end of the year 2030, it will be increased up to $277.27 \mathrm{~kg} /$ hectare.

Table 4: Forecast of fertilizers consumption upto 2030

\begin{tabular}{lllll}
\hline $\begin{array}{l}\text { Sl. } \\
\text { No. }\end{array}$ & Year & $\begin{array}{l}\text { Total } \\
\text { requirement } \\
\text { (million tons) }\end{array}$ & $\begin{array}{l}\text { GCA } \\
\text { (million ha) }\end{array}$ & kg/ha \\
\hline 1 & 2021 & 39.70 & 201.14 & 197.35 \\
2 & 2022 & 41.35 & 201.76 & 204.94 \\
3 & 2023 & 43.07 & 202.38 & 212.82 \\
4 & 2024 & 44.87 & 203.00 & 221.01 \\
5 & 2025 & 46.74 & 203.62 & 229.52 \\
6 & 2026 & 48.68 & 204.24 & 238.36 \\
7 & 2027 & 50.71 & 204.86 & 247.54 \\
8 & 2028 & 52.82 & 205.48 & 257.08 \\
9 & 2029 & 55.02 & 206.10 & 266.98 \\
10 & 2030 & 57.32 & 206.72 & 277.27 \\
\hline
\end{tabular}

Source: Authors calculations.

The forecast suggests that by 2025 , per hectare fertilizer consumption will exceed the level of 230 $\mathrm{kg}$, which will be double the amount of current usage of fertilizer. However, this is still below the level of the intensity of usage of fertilizer in other countries. According to the World Bank data, per hectare fertilizer consumption in Bangladesh during the year 2013 was $208.7 \mathrm{~kg}$, which is higher than India though arable land in Bangladesh is lesser than India and likewise China, Colombia and Malaysia's fertilizers consumption rate were $364.4 \mathrm{~kg}, 648.8 \mathrm{~kg}$ and $1726.6 \mathrm{~kg}$, respectively, which was higher than India during the same period. No wonder these countries experienced higher crop productivity too. Data shows that the fertilizer consumption in 2013 for the middle income countries was $132.1 \mathrm{~kg}$ and that of upper middle income countries this was $144.7 \mathrm{~kg}$. This means fertilizer intensity in India matches with most of the countries; however, we still have scope to improve the same.

So, it is clear from the data that the domestic production of fertilizers has increased over the period. In case of $\mathrm{N}$ and $\mathrm{P}$, the country is near to achieving self sufficiency. However, addition of new capacity and efficient use of existing capacity is still lagging behind. If we compare the growth rates, imports have shown a higher growth. This has many implications with the country being completely dependent on imports for $\mathrm{K}$ fertilizers, which adds to the burden upon the government. Thus, policies have to be adopted to create encouraging environment for domestic industries and existing industries have to increase their efficiency. The increasing requirement should be met with increasing domestic production, instead of increasing imports. International prices of fertilizers are also increasing, adding to the fiscal burden of the government. Conducive policy structure for domestic production is a must to reduce the subsidy burden of the government.

\section{CONCLUSION}

Fertilizer consumption in India is still lower than many countries and it comprises an important part of the modern consumable inputs structure of the changing agricultural scenario. The structure of fertilizer industry is an interesting mix of government support and market forces. This characteristic feature has lead to changes in consumption of fertilizers with the changes in government policies. There are several factors that contribute to the increase in fertilizer consumption. Among them, MSPs, increase in the area under 
irrigation, availability of credit plays an important role in determining the demand of fertilizers from the field. On the contrary, domestic production, total imports of fertilizers, and subsidy extended to the sector are significantly affecting the supply of fertilizers in the country. Increase in the output prices, area under irrigation and credit availability are all institutional factors. They show a decent growth over time. The forecast suggested that by 2030 the total fertilizer demand will reach a level of around 57 million tons. The rate of consumption of fertilizers by the same time will be $277 \mathrm{~kg} / \mathrm{ha}$. Thus, the analysis articulates that we need a concerted policy response for the encouragement of domestic production and capacity utilization, reduced dependence on imports, efficient management of subsidy for the sector, promoting balanced use of fertilizers with the help of awareness programmes and improvement in agricultural education, and efforts to reduce the huge variations in the use of fertilizers across regions.

\section{REFERENCES}

Agricultural Statistics at a Glance. 2014. Directorate of Economics and Statistics, Department of Agriculture \& Cooperation, Ministry of Agriculture, Government of India, New Delhi.

All India Area, Weighted Monthly, Seasonal, and Annual Rainfall 2016. https://data.gov.in/sites/default/ files/datafile/All_India_Area_Weighted_Monthly_ Seasonal_And_Annual_Rainfall.xls

FAI, Fertilizer Statistics 2014. The Fertilizer Association of India, New Delhi.

FAO. 2015. Fertilizer Use by Crop in India, FAO, Publication, Rome

FAO. 2017. The future of food and agriculture - Trends and challenges. FAO, Publication, Rome.

Indian Fertilizer Scenario. 2014. Economics and Statistics Wing, Department of Fertilizers, Ministry of Chemicals \& Fertilizers, New Delhi.

Jaga, P.K. and Patel, Y. 2012. An Overview of Fertilizer Consumption in India: Determinants and Outlook for 2020 A Review, Int. J. Scientific Engin. Techn., 1(6): 285-291.
Mala, P. 2013. Fertilizer Scenario in India, Int. J. Soc. Sc. E Interdisciplinary Res., 2(1): 62-72.

Malik, R.P.S. and Sekhar, C.S.C. 2007. Factors Affecting Fertilizer Consumption in Haryana, Research Study No. 2007/4, Agricultural Economics Research Centre, University of Delhi, Delhi.

Nagaraj, R. 1983. Determinants of Fertilizer Use in Indian Agriculture, Eco. and Pol. Weekly (Review of Agriculture), 18(13): A2- A15.

Ramappa, K.B., Jadhav, V. and Manjunatha, A.V., 2020. Comparative economics of Neem coated urea vis-a-vis normal urea: evidence from a field-based study in the Indian context. Eco. Affa., 65(2): 275-284.

Senapati, P. 2014. A Study of Agricultural Inputs Marketing in India, Indian Streams Res. J., 4(5): 2-6.

Sharma, Paul, V. and Thaer, H. 2011. Demand for Fertilizer in India: Determinants and Outlook for 2020, W.P. No. 2011-04-01, IIMA Research and Publications, IIMA.

Sharma, Paul, V. and Thaker, H. 2011. 'Economic Policy Reforms and Indian Fertilizer Industry', Allied Publishers, New Delhi.

Singh, H. and Solanki, Ramkrishna Singh, 2014. Factors Influencing the Use of Fertilizers in Agriculture of Madhya Pradesh in India, Int. J. Sci. Res. Math. Statis. Sci., 1(2): 118-23.

Tiwari, K.N. 2001. The Changing Face of Balanced Fertilizer Use in India, Better Crops Int., 15(2): 24-27.

Venkatesan, S. and Arulraj, A. 2014. Fertilizer Market in India- An Insight on Demand Determinants, Global J. Res. Ana., 3(1): 37-38.

Venkatesh, P. and Nithyashree, M.L. 2014. Institutional Changes in Delivery of Agricultural Inputs and Services to Farm Households in India, Agril. Econ. Res. Rev., 27(1): 85-92.

Venugopal, P. 2004. State of the Indian Farmer: A Millennium Study, Input Management, Academic Foundation, New Delhi, 8(1): 125-135.

Parama, V.R. and Munawery, A. 2012. Sustainable Soil Nutrient Management. J. Indian Inst. Sci., 92(1): 1-16. 
